\title{
Consideraciones terminológicas sobre la evolución del léxico de la fortificación abaluartada*
}

\author{
Marta Sánchez Orense \\ Universidad de Murcia
}

\section{RESUMEN}

El presente trabajo tiene como objetivo dibujar una panorámica sobre la evolución del léxico de la fortificación abaluartada desde su nacimiento, en el siglo XVI, hasta su momento de mayor esplendor, el XVIII. Para ello, partimos de un punto intermedio, la segunda mitad del XVII, a la que pertenece el Epitome de la fortificación moderna (1669) de Zepeda. Así, se extraerá, primero, el léxico de especialidad definido en el capítulo II de la segunda parte de sus "Preludios geométricos para la Arquitectura militar" para compararlo y analizarlo, después, con el que contienen las primeras manifestaciones en lengua española de la tratadística de fortificación, de finales del XVI, así como una de las últimas, el Tratado de fortificación (1772) de Lucuze.

Palabras clave: lexicología, lexicografía, semántica, fortificación

\section{AbstRact}

In this paper we attempt to draw an overview on the evolution of the lexicon of bastionated Fortification from its origins, in the 16th century, until

\footnotetext{
" Este trabajo se enmarca en las directrices del proyecto de investigación Corpus para el estudio de la lengua española científica y matemática del siglo VII (19296/PI/14), financiado por la Fundación Séneca.
}

https://doi.org/10.18800/lexis.201802.006 
its apogee, during the 18th. To do this, we start from an intermediate point, the second half of the 17th, when the Epitome de la fortificacion moderna (1669), written by Zepeda, was published. In that way, we select the specialized vocabulary which is defined in chapter II of the second part of its "Preludios geométricos" with the purpose of comparing and analysing this vocabulary with the lexicon contained in the first treatises of the Fortification in Spanish language, from the final years of the 16th, until the Tratado de fortificación (1772) of Lucuze.

Keywords: lexicology, lexicography, semantics, fortification

\section{Introducción}

Como es bien sabido, a lo largo de toda la segunda mitad del siglo XV se suceden en la Europa occidental una serie de importantes transformaciones y cambios, los cuales desembocarán inevitablemente en el fin de la Edad Media, así como en el inicio de la Edad Moderna. En este desenlace final, se revelarán como decisivos aspectos tan destacados como la invención de la imprenta, los viajes y los descubrimientos geográficos, además del afianzamiento del Estado moderno. A todo ello se suma el triunfo de un nuevo movimiento cultural, el Renacimiento, cuyos principales exponentes se hallan en el campo de las artes, si bien trajo consigo también importantes renovaciones en el ámbito de las ciencias, de ahí que suela destacarse por su transcendencia y amplitud.

De hecho, una de las ramas del conocimiento en las que más se dejó sentir la influencia de la mentalidad renacentista fue la de la milicia, de tal forma que con el inicio de la Edad Moderna comienza a hablarse de una verdadera revolución militar ${ }^{1} \mathrm{y}$, en consecuencia, de una nueva manera de concebir y afrontar la guerra. Pues bien, todos los investigadores coinciden en señalar la campaña realizada

\footnotetext{
1 “En el Renacimiento tiene lugar una auténtica 'revolución militar', un cambio profundo en las armas, técnicas y tácticas, en los modos de reclutamiento, organización y financiación de los ejércitos, en las justificaciones y reglamentaciones jurídico-políticas de los conflictos bélicos, en sus implicaciones económicas, geopolíticas, sociales e intelectuales” (Campillo 2008: 26).
} 
en Italia en 1494 por las tropas francesas de Carlos VIII como el punto de inflexión que separa la guerra medieval de la moderna, entre otras razones porque con aproximadamente 18000 hombres y nuevos adelantos artilleros el bando francés consiguió batir rápidamente las hasta entonces sólidas murallas italianas (Parker 2002: 35).

Por tanto, la evolución y transformación de la artillería suele ser lo más destacado dentro de la revolución militar del Renacimiento. Es más, la mayor aplicación de la pólvora al lanzamiento de los proyectiles desemboca en un problema anteriormente inexistente: el desequilibrio generado entre los medios de ataque y los de defensa. Debe notarse, en definitiva, que los avances en el terreno artillero condicionaron el nacimiento de la llamada fortificación abaluartada. ${ }^{2}$ Es la nueva mentalidad moderna, no obstante, la que propicia aplicaciones más efectivas de la pólvora en los conflictos bélicos y, en consecuencia, la posterior consagración de esa incipiente e innovadora modalidad arquitectónica defensiva. En palabras de Merino Peral, "fueron necesarios los cambios amplios, generales, que acontecieron en la nueva situación histórica del Renacimiento, para poder extraer consecuencias de ese material y demás 'ingenios"” (2002: 27).

Inmersos en este ambiente, no fueron pocos los hombres del siglo XVI que se lanzaron a la confección de obras sobre fortificación, de tal forma que a lo largo de aquel siglo "se llevaron a las imprentas europeas un número indeterminado de libros dedicados al tema de la arquitectura y la ingeniería militar, los llamados tratados de arquitectura militar o tratados de fortificación" (Galindo Díaz 1996: 1).

2 Díaz Capmany señala que

La fortificación abaluartada es una especie dentro del género de la fortificación, y como tal especie está compuesta por unidades que tienen caracteres comunes por los cuales se asemejan entre sí y se distinguen de las de otras especies. Esta especie está formada por el conjunto de obras defensivas levantadas, en el mundo occidental, desde el siglo XVI hasta principios del siglo XIX. Proyectada para hacer frente a los destructivos efectos de la artillería, esta fortificación fue necesaria y útil, desde el momento en que aquella adoptó los materiales de bronce, de ánima lisa, y los proyectiles esféricos metálicos, hasta que entraron en servicio los materiales de ánima rayada, con proyectiles cilíndricos de cabeza ojival (2004: 14). 
Ahora bien, para encontrar auténticos exponentes de este género textual en lengua castellana habrá que esperar hasta finales del siglo XVI, concretamente hasta el año 1598, cuando se publica la Teórica y práctica de fortificación de Cristóbal de Rojas, a la que le sigue el Examen de fortificación (1599) de González de Medina Barba, textos que suponen los dos únicos tratados de fortificación españoles del siglo XVI.

Por el contrario, constituyen un nutrido conjunto los libros que en torno a esta temática escribieron durante ese siglo los italianos, lo que no debe sorprendernos si tenemos en cuenta que fue precisamente Italia la plaza más acosada por los efectos de los nuevos cañones. ${ }^{3}$ No quiere esto decir, no obstante, que nuestra lengua no contara con antecedentes para la Teórica y práctica de fortificación (1598), de hecho, a lo largo del siglo XVI, especialmente durante su segunda mitad, aparecen varios tratados militares escritos por españoles, entre los que destacamos los siguientes por formar parte del corpus del Diccionario de la Ciencia y de la Técnica del Renacimiento (DICTER) (Mancho s/f): ${ }^{4}$

- Montes, Diego (1537): Instrucción y regimiento de guerra. Zaragoza: George Coci.

- García de Palacio, Diego (1583): Diálogos militares. México: Pedro Ocharte.

- Álaba y Viamont, Diego de (1590): El perfeto capitán instruido en la diciplina militar y nueva ciencia de la Artillería. Madrid: Pedro Madrigal.

- Collado Lebrixa, Luys (1592): Plática manual de Artillería. Milán: ${ }^{5}$ Pablo Gotardo Poncio.

\footnotetext{
3 Para examinar el contenido y características de los más significativos, como los de Giorgio Martini y Girolamo Cataneo, véase Galindo Díaz (1996: 35-50).

4 Adicionalmente, este contiene otros dos de principios del siglo XVII: Discurso del Capitán Cristóval Lechuga, en que trata de la Artillería y de todo lo necessario a ella (1611) y Tratado de la Artillería (1613) de Diego Ufano.

5 Como puede constatarse, algunos de estos tratados de milicia y artillería se imprimieron fuera de nuestras fronteras, lo que, en palabras de Bravo Nieto (1994: 73), "revela tanto el interés como la altura científica de los autores hispanos”.
} 
- Mendoça Bernardino de (1595): Theórica y práctica de guerra. Madrid: Viuda de P. Madrigal.

- Mosquera de Figueroa, Christóval (1596): Comentario en breve compendio de disciplina militar. Madrid: Luis Sánchez.

Si bien ninguna de estas obras constituye auténticos tratados de fortificación, al no incluir entre sus principales intereses la construcción material de fortificaciones, no debe desdeñarse su trascendencia por lo que respecta a la ingeniería militar. En este sentido, la principal contribución española a la literatura sobre arquitectura defensiva en el siglo XVI parece estar conformada por un grupo de obras dedicadas a la artillería, entre las que destacan las de Álaba y Viamont y Collado de Lebrija, según sostienen autores como López Piñero (1979: 105-106); a las que habría que sumar las centradas en otros asuntos militares, como la táctica y disciplina bélicas y demás cuestiones relativas al arte de la guerra, temáticas abordadas en mayor o menor medida por el resto de tratados mencionados.

En cualquier caso, de la preponderancia de los tratadistas italianos en el siglo XVI se pasa a la de los franceses y españoles en el cambio de centuria. Dentro de esta segunda posibilidad, que es la que centra nuestra atención, Galindo Díaz contabiliza hasta 37 tratados de fortificación escritos en español y publicados durante el siglo XVII. De estos, destaca, "por la claridad de su exposición y profundidad de sus contenidos" (1996: 80), el Epitome de la fortificación moderna... ${ }^{6}$ de Alonso de Zepeda y Adrada, ${ }^{7}$ el cual fue publicado pasada ya la primera mitad del siglo XVII. Por fin, en el siglo XVIII español sobresale la Real Academia de Matemáticas de

\footnotetext{
6 Como era usual en aquella época, el título completo de esta obra es considerablemente más largo, a saber: Epitome de la fortificación moderna, assí en lo regular como en lo irregular, reducida a la regla y al compás por diversos modos y los más fáciles para mover la tierra; y otros diversos tratados de la Perspectiva, Geometría práctica y del modo de sitiar y defender las plazas, $y$ de la construcción de las baterias y minas, $y$ artificios de fuego para arrojar al enemigo.

7 “Militar español, 'teniente de maestro de campo', general y gobernador de Tholen, Países Bajos” (López Piñero, Glick, Navarro Brotóns y Portela Marco 1983: s. v. Zepeda y Adrada, Alonso de).
} 
Barcelona, "fundada, en virtud de un Real Despacho del rey Felipe V, el 22 de enero de 1700" (Galindo Díaz 1996: 171), entre cuyos directores despunta Pedro de Lucuze, sobre todo por haber logrado durante su largo mandato, desde 1738 hasta 1779, la consolidación de este centro de enseñanza como el único, además de prestigioso, para la enseñanza de ingenieros militares en toda España.

Es en este contexto pedagógico en el que deben situarse sus Principios de fortificación (1772), los cuales contienen, como su propio subtítulo indica, "las definiciones de los términos principales de las obras de plaza y de campaña”. Esta novedad, ${ }^{8}$ fruto de su marcado carácter didáctico, junto con el hecho de que es en el siglo XVIII, centuria en que se compone esta obra, cuando la fortificación abaluartada alcanza sus más altas cotas de perfección, consecuencia lógica de su ya larga trayectoria, lo que explica considerar este tratado como uno de los más completos e importantes de nuestra historia.

Tras esta breve panorámica en torno a la historia de los tratados de la fortificación abaluartada en lengua castellana, nos proponemos analizar el léxico especializado presente en el Epitome de la fortificación moderna (1669), así como sus respectivas definiciones en él contenidas, para, después, comparar ambas cuestiones con la situación reflejada por el "Glosario de fortificación y arte militar renacentistas” (Sánchez Orense 2012b) y por los Principios de fortificación (1772) de Pedro de Lucuze. De esta forma, esperamos poder contribuir a dibujar una panorámica de la evolución del léxico de la fortificación moderna, así como de sus correspondientes definiciones, desde sus primeras manifestaciones hasta una de las últimas.

\footnotetext{
Aunque, como comprobaremos, también el Epitome de la fortificación moderna (1669) de Alonso de Zepeda cuenta con definiciones para los términos de la arquitectura militar, las cuales analizaremos, no es hasta los Principios de fortificación de Lucuze, del año 1772, cuando la recopilación de los tecnicismos se convierte en exhaustiva y el principal objetivo consiste precisamente en su explicación. De hecho, es tan significativa esta vertiente dentro de su obra, que el propio Lucuze, en su prólogo “Al lector", no la califica de tratado, sino de diccionario.
} 


\section{El Epitome de la fortificación moderna y los tecnicismos de fortificación presentes en sus "Preludios geométricos"}

Según Galindo Díaz, el tratado de Zepeda es "uno de los más importantes textos de fortificación españoles del siglo XVII, al estudiar [...] aspectos relacionados con la construcción material de fortificaciones intercalando datos apoyados matemáticamente con observaciones prácticas" (1996: 86). Este libro se compone de diez tratados a los que anteceden unos "Preludios geométricos para la Arquitectura militar", los cuales se dividen a su vez en dos partes: en la primera, a la que pertenecen dieciséis capítulos, se aborda la geometría euclidiana, mientras que es la segunda, que consta de otros siete, la centrada en exclusiva en el tema de la arquitectura militar. ${ }^{9}$ Ahora bien, para nuestro propósito, el capítulo más relevante es el segundo de esos siete, al estar consagrado a la enumeración y explicación de los términos de fortificación más importantes.

Así, en la siguiente tabla, además de consignar cada una de las voces especializadas contenidas en esas páginas $-\mathrm{y}$ en su misma forma, sin adaptarlas a las actuales normas ortográficas-, procedemos a su clasificación por campos semánticos, esto es, por las realidades de fortificación a las que aluden, de acuerdo con sus respectivas definiciones:

En resumen, el capítulo II de la segunda parte de los "Preludios geométricos" del Epitome de la fortificación moderna contiene las definiciones y explicaciones de los setenta tecnicismos que, según Alonso de Zepeda, constituyen el léxico básico de la fortificación abaluartada, conjunto en el que, de acuerdo con la distribución de la tabla 1, despunta especialmente el campo semántico de las "partes o elementos de un recinto fortificado". Tanto es así que el grupo formado por estas palabras supone más del $65 \%$ del total del vocabulario contemplado.

\footnotetext{
9 De acuerdo con Sánchez Martín, en la época moderna adquiere una gran relevancia la ciencia geométrica, cuya aplicación resulta fundamental para el correcto desempeño de cualquier disciplina, incluida la fortificación (2013: 149).
} 


\section{Tabla 1}

\begin{tabular}{|c|c|}
\hline $\begin{array}{l}\text { CONSTRUCCIONES } \\
\text { DEFENSIVAS }^{10}\end{array}$ & $\begin{array}{l}\text { villa o ciudad, contramina, través, }{ }^{11} \text { fortín o fuerte de } \\
\text { campaña, palizada, frasa, }{ }^{12} \text { barrera, molinete o torno, } \\
\text { cavallo de frisa. }\end{array}$ \\
\hline $\begin{array}{l}\text { Partes o elementos de un } \\
\text { recinto fortificado }\end{array}$ & $\begin{array}{l}\text { ciudadela o castillo, }{ }^{13} \text { retirada (para los franceses, } \\
\left.\text { donjón o reduto }{ }^{14}\right) \text {, plaza de armas, muralla, } \\
\text { terraplén, }{ }^{15} \text { parapeto, banqueta, bordo de la muralla, } \\
\text { contraforte, cordón, baluarte, facie o frente, travez o } \\
\text { flanco, }{ }^{16} \text { falsabraga, casamata o plazabaja bajaza }{ }^{17} \text { plalta, } \\
\text { cañonera, merlón, orejón, poterna, puerta, rastillo, } \\
\text { órgano, puente, foso, refoseto o cuneta, contraescarpa, } \\
\text { reserva o contraguardia, cavallero, plataforma, } \\
\text { estrada encubierta, esplanada, fortificación de afuera, } \\
\text { media luna, ravelin, tenaza, ornabeque, corona. }\end{array}$ \\
\hline Pertrechos ${ }^{18}$ & césped o tepe, candelero, fagina, salchichón, abrojo. \\
\hline Formas constructivas & declivio, caýda o falda; escarpa. \\
\hline Localizaciones espaciales & Padastro. ${ }^{19}$ \\
\hline Herramientas de diseño & porfil. ${ }^{20}$ \\
\hline
\end{tabular}

10 Con esta denominación nos referimos a todas aquellas fábricas o edificios que, si bien en ciertos casos podían formar parte de un recinto mayor, lo normal es que fueran ya por sí solas defensas lo suficientemente efectivas, a diferencia del siguiente grupo, integrado por los miembros de una fortaleza, esto es, por aquellos elementos defensivos cuya construcción solo tenía sentido dentro de un conjunto.

11 "Suelen avanzar sobre la esplanada o formar en lugares de difícil acceso, o en otros que no pueden flanquearse en otra forma, unos traveses a modo de dientes de cierra, que llama el françés redants” (Zepeda 1669: 55). Así, el través podría definirse como la "obra o defensa que, tanto por parte de los sitiadores como por parte de los sitiados, suele levantarse en lugares estrechos para tratar de impedir el paso al enemigo" (Sánchez Orense 2012b: s. v.).

12 "Es una especie de palizada hecha de maderos quadrados o cortados por los quatro lados, y se suelen colocar en la mitad del altura de la muralla, mirando sus puntas hazia el fosso, para embarazar las surpresas y evitar que ninguno vaya de noche por la muralla al fosso" (Zepeda 1669: 56).

13 "Ciudadela o castillo es una fortificación de quatro o cinco baluartes que se haze para guardar una ciudad siendo muy estendida en su recinto, o para subgetarla siendo su población conquistada o sospechosos sus moradores" (Zepeda 1669: 39). Esto es, este tipo de defensa solo se levantaba, si era preciso, dentro de una obra de fortificación mayor, concretamente la de una villa; es por esto por lo que consideramos su pertenencia al campo nocional de las "partes o elementos de un recinto fortificado". Ahora bien, como después detallaremos, parece ser que castillo podía hacer también referencia a una completa obra defensiva, concretamente a la fortaleza construida para ocupar puestos de importancia estratégica, como los pasos de un río, las entradas de caminos, las montañas, etc. Por otro 


\subsection{El cotejo con otras obras militares: resultados}

Como era esperable, en el rastreo de todas esas voces tanto en los tratados militares españoles del siglo XVI — de manera prioritaria en los dos de fortificación existentes en ese siglo- como en los Principios de fortificación de Lucuze (1772), han resultado ser mayoría las coincidencias, tanto en su forma léxica como en su

lado, el mismo Zepeda admite que el "castillo propiamente es una fortaleza a la antigua hecha de torres redondas o quadradas de piedra, con sus fosos; y algunos están rodeados de una barbacana, como se vee en nuestra España aún del tiempo que gimió debajo del yugo del africano" (1669: 39-40). Así, el término castillo contaba ya con una larga tradición medieval, lo que, en nuestra opinión, como ya sugerimos, explicaría que, a pesar de su existencia, se recurriese a principios del siglo XVI al italianismo ciudadela para este caso concreto, lo que trajo consigo el problema terminológico de la sinonimia, si bien, poco a poco, y por sus evidentes connotaciones de elemento antiguo, esta segunda posibilidad designativa logró imponérsele (Sánchez Orense 2013a: 45).

14 “A esta retirada llaman los franceses donjón, y reduto siendo en una villa” (Zepeda 1669: 40). Efectivamente, donjón parece provenir del francés donjon (cf. TLF de P. Imbs 1971-1986); sin embargo, para reducto suele barajarse más bien un origen italiano, que según Corominas y Pascual (1980-1991) sería también el de la palabra gala redoute: “Reducto [1595], castellanización culta del it. ridotto 'íd.' [s. XIV], de donde procede también el fr. redoute [s. XVII]” (DECH: s. v. aducir) (Corominas y Pascual 1980-1991). Así, esta filiación podría explicar la mención al francés por parte de Zepeda en este caso. 15 El tratado de Zepeda muestra ya claramente el triunfo de este galicismo en detrimento del italianismo terrapleno, típico de los tratados militares españoles del siglo XVI. Para más detalles, véase Sánchez Orense (2013a: 43).

16 De nuevo se comprueba en el tratado analizado la victoria de una voz de origen galo, en este caso de flanco, sobre su oponente italiana, fianco, con la consecuente caída en desuso de esta. Véase al respecto Sánchez Orense (2013a: 44).

17 "En las murallas revestidas de piedra o ladrillo se suelen hazer cazamatas, que llama el françés plazas bajas [...]. Se pueden definir las casamatas diciendo son ciertas bóbedas donde se puede alojar la artillería para la defensa del fosso" (Zepeda 1669: 49-50). El hecho de que este autor iguale la casamata a la plaza baja vendría a confirmar que ya en su época, mediado el siglo XVII, lo normal era construir este elemento defensivo de manera descubierta, frente a las primeras casamatas de la fortificación abaluartada, las cuales consistían en cámaras abovedadas dentro del terraplén de las fortalezas. Para más detalles sobre la invención y evolución de las casamatas, véase Lucuze (1772: 58-61).

18 Toda clase de materiales e instrumentos, como pueden ser armas o máquinas, necesarios para cualquier empresa militar” (Sánchez Orense 2012b: s. v.).

19 "Es un lugar que se levanta sobre otro por lo menos 9 pies, y puede ser simple, compuesto, en precipicio, de frente, por los lados, y que descubre la brecha por las espaldas” (Zepeda 1669: 54).

20 "Es una sección o corte perpendicular sobre el horizonte que representa todas las alturas de las fortificaciones de una plaza y el espesor de sus murallas” (Zepeda 1669: 56). 
significado. Ahora bien, no resultan tampoco escasos los ejemplos de discordancias entre lo reflejado por las más antiguas obras manejadas frente a la de Zepeda, por un lado, así como entre esta y la de Lucuze, por otro. Es decir, hemos podido comprobar que no todos los tecnicismos del siglo XVII extraídos del Epitome de la fortificación moderna constan de su correspondiente e idéntico paralelo en la centuria renacentista o en la ilustrada, al menos por lo que respecta a las obras consultadas.

Así, nos disponemos a ofrecer en detalle, seguidamente, estas particularidades, para lo cual hemos creído conveniente establecer tres apartados distintivos.

\subsubsection{Voces ausentes}

Dentro de los contrastes detectados, sobresale especialmente el conjunto de las voces de especialidad consignadas y explicadas por Alonso de Zepeda que, sin embargo, no cuentan con antecedentes en el siglo XVI. En la siguiente tabla especificamos, además, para cada una de ellas si dicha situación se hace extensible al tratado de Lucuze:

\section{Tabla 2}

\begin{tabular}{|l|c|l|}
\hline Términos & $\begin{array}{l}\text { Tratados del } \\
\text { siglo XVI }\end{array}$ & \multicolumn{1}{c|}{ Tratado de Lucuze } \\
\hline Frasa & $\varnothing$ & $\varnothing$ \\
\hline $\begin{array}{l}\text { Caballo de } \\
\text { frisa }\end{array}$ & $\varnothing$ & $\begin{array}{l}\text { "El caballo de frisa es una especie de barrera o } \\
\text { estacada portátil que consiste en un madero de } \\
\text { diez pies de largo y uno de grueso, agujereado } \\
\text { en cruz, por donde atraviesan palos de tres } \\
\text { pulgadas de grueso y ocho pies de largo cuyos } \\
\text { extremos terminan en puntas de hierro. Sirven } \\
{[\ldots] \text { para guarnecer la brecha o un puesto de }} \\
\text { tropas, especialmente contra la caballería" } \\
\text { (Lucuze 1772: 83). }\end{array}$ \\
\hline
\end{tabular}




\begin{tabular}{|l|c|l|}
\hline Términos & $\begin{array}{c}\text { Tratados del } \\
\text { siglo XVI }\end{array}$ & \multicolumn{1}{c|}{ Tratado de Lucuze } \\
\hline Poterna & $\varnothing^{21}$ & $\begin{array}{l}\text { "Las poternas son unas puertas menores que las } \\
\text { principales y mayores que los portillos, de cinco a } \\
\text { seis pies de ancho y ocho de alto, lo que basta para } \\
\text { comunicarse la plaza con las obras exteriores. Su } \\
\text { propiolugares el más guardado o menos descubierto: } \\
\text { sitúanse regularmente en la contrahondidura o línea } \\
\text { retirada, entre el flanco y el orejón, o bien al extremo } \\
\text { o en medio de la cortina, baxando desde el nivel de } \\
\text { la plaza por una bóveda inclinada de quatro varas de } \\
\text { ancho que atraviesa el terraplén y sale al fondo del } \\
\text { foso quando es seco, o a la superficie del agua si es } \\
\text { inundado" (Lucuze 1772: 78). }\end{array}$ \\
\hline Órgano & $\varnothing$ & $\begin{array}{l}\text { "El órgano suele ponerse detrás de la puerta } \\
\text { principal, en medio de la bóveda, ocupando toda } \\
\text { la latitud. Consiste en gruesas estacas con las } \\
\text { puntas herradas que, pasando por los agujeros de } \\
\text { un tablón horizontal, penden de un torno elevado } \\
\text { en que se envuelve la cuerda de cada estacada y, } \\
\text { haciéndole rodar, caen a un tiempo todas y cierran } \\
\text { tan fuertemente el paso, que los enemigos, aunque } \\
\text { rompan o ganen la puerta, son detenidos por el } \\
\text { órnago [sic], que da tiempo a la guarnición para } \\
\text { rechazarlos [...]" (Lucuze 1772: 81-82). }\end{array}$ \\
\hline Hornabeque & $\varnothing$ & $\begin{array}{l}\text { "De las grandes obras exteriores, es la mejor el } \\
\text { bornabeque, pues presenta a la campaña un frente } \\
\text { fortificado compuesto de una cortina y dos medios } \\
\text { baluartes, semejante al de la plaza. Su colocación } \\
\text { puede ser delante de la cortina y sobre un baluarte, } \\
\text { según el fin a que se destina y conforme a la } \\
\text { disposición del terreno [...]" (Lucuze 1772: 55). }\end{array}$ \\
\hline
\end{tabular}

21 "Suelen fabricarse cubiertas de los orejones unas puertesillas falsas que caen sobre la superficie del agua del fosso, o sobre su nibel (si es seco), para salir al enemigo y repelerle del fosso y de las fortificaciones de afuera sin ser descubiertos, ni necessitar de que se bajen los puentes principales. A los quales llama el francés poternas [...]” (Zepeda 1669: 50-51). De nuevo se observa cómo el autor del siglo XVII hace mención a una etimología francesa, quizá porque, efectivamente, los galicismos constituyen uno de los tipos más importantes de préstamo dentro del vocabulario militar, especialmente en el de aquella centuria (véase Varela Merino 2009).

22 En algunos tratados se habla también de puertas falsas, las cuales reciben el nombre de postigo ( $c f$. Sánchez Orense 2012b). Ahora bien, este término, frente a poterna, parece 


\begin{tabular}{|c|c|l|}
\hline Términos & $\begin{array}{c}\text { Tratados del } \\
\text { siglo XVI }\end{array}$ & \multicolumn{1}{c|}{ Tratado de Lucuze } \\
\hline Corona & $\varnothing$ & $\begin{array}{l}\text { "La corona es la mayor entre las obras accidentales, } \\
\text { que suele llamarse hornabeque doble porque } \\
\text { se compone de dos hornabeques sencillos, } \\
\text { presentando a la campaña dos frentes fortificados; } \\
\text { esto es, un baluarte entero, dos cortinas y dos } \\
\text { medios baluartes a los extremos [...]"24 (Lucuze } \\
\text { 1772: 56). }\end{array}$ \\
\hline
\end{tabular}

En definitiva, de los seis términos contenidos en la tabla 2, los cuales, como ya hemos advertido, no se encuentran en los textos que conforman el corpus del DICTER, solo uno, frasa, está asimismo ausente de la obra de Lucuze. Ahora bien, conviene destacar su particularidad, pues, al no hallarse documentación adicional, ${ }^{25}$ su condición de hápax resulta más que probada. En cualquier caso, no son solo seis los vocablos empleados por Zepeda cuya presencia no se da en los tratados renacentistas. Así, los siguientes cuatro se encuentran en esa misma situación, los cuales ofrecemos al margen de los anteriores por tratarse de dos parejas de sinónimos:

poseer un carácter mucho más general, al hacer referencia a cualquier puerta disimulada y no a una concreta y con exacta ubicación dentro de una fortaleza abaluartada.

23 "Corona son ciertas fortificaciones con que se cubre y fortifica más los cuernos del ornabeque” (Zepeda 1669: 55-56).

${ }_{24}$ Es especialmente patente en este caso el contraste entre la escasa y poco precisa información aportada por Zepeda y la abundante y detallada ofrecida por Lucuze, lo cual puede deberse, primero, al contexto didáctico en el que este último inscribe su obra, pero también, en segundo lugar, a que es en el siglo XVIII cuando el sistema de la fortificación abaluartada logra completarse y perfeccionarse al máximo fruto de su larga evolución. En este sentido, resultan minuciosas y sumamente clarificadoras las varias figuras con las que Lucuze complementa sus explicaciones.

25 Tras una exhaustiva búsqueda, solo hemos detectado la siguiente ocurrencia de frasa, la cual, al responder a una recopilación del léxico especializado contenido precisamente en la obra que aquí analizamos, no posee trascendencia: "Léxico empleado en Fortificaciones trae el 'Epítome de Alonso de Zepeda y Adrada, Teniente de Maestro de Campo, General y Governador del Tholhuys', impreso en Bruselas en 1669 [...]. El glosario técnico de arquitectura militar se introduce a modo de vocabulario en el capítulo II de la segunda parte de los Preludios, pág. 39 y siguientes. Y he ahí los vocablos provistos de definición: ciudadela, castillo, [...] palizada, frasa (palizada en la mitad del altura de la muralla) [...]" (Terradas 1946: 185-186). Debemos la localización de este pasaje al Corpus del Nuevo diccionario bistórico del español $(C D H)$ de la RAE. 


\section{Tabla 3}

\begin{tabular}{|l|c|l|}
\hline Términos & $\begin{array}{c}\text { Tratados del } \\
\text { siglo XVI }\end{array}$ & \multicolumn{1}{c|}{ Tratado de Lucuze } \\
\hline Molinete & $\varnothing$ & $\begin{array}{l}\text { "El molinilllo26 consiste en dos maderos } \\
\text { cruzados y unidos que sobre otro fixo en tierra } \\
\text { se mueven horizontalmente acia todas partes. } \\
\text { Sirve en un paso estrecho para que salga o entre } \\
\text { un hombre solo a la vez, y no pase caballo } \\
\text { alguno" (Lucuze 1772: 83). } \\
\varnothing\end{array}$ \\
\hline Torno & $\varnothing$ & $\begin{array}{l}\varnothing \\
\text { "Es muy ventajosa la contraguardia, pues cubre } \\
\text { las caras del baluarte, y las suyas toman la defensa } \\
\text { de los rebellines, de suerte que una plaza cubierta } \\
\text { de rebellines y contraguardias tiene las obras } \\
\text { convenientes a su defensa. El terraplén, parapeto } \\
\text { y foso es en la forma que se ha dicho del rebellín. } \\
\text { La contraguardia ha de quedar descubierta del } \\
\text { rebellín y, por consiguiente, sin parapeto acia } \\
\text { esta parte [...]" (Lucuze 1772: 44-45). }\end{array}$ \\
\hline
\end{tabular}

En consecuencia, en la primera tabla dábamos cuenta de seis voces sin correlato sinonímico, por lo que su ausencia en los tratados renacentistas implicaba la inexistencia también de los seis conceptos con ellas referidos; en este caso, en cambio, al encontrarnos ante voces equivalentes, serían únicamente dos, y no cuatro, las realidades especializadas aún no descubiertas o manejadas por los primeros especialistas de la fortificación de nuestro país. Por el contrario, el uso por parte de Lucuze de una de las dos denominaciones de dichos pares sinonímicos — de molinillo, en un caso, y de contraguardia, en el otro- vendría a confirmar la utilidad concedida aún por el siglo XVIII a estas construcciones de la fortificación abaluartada.

26 Como se constata, hay una pequeña diferencia entre el término exacto empleado por Zepeda y el preferido por Lucuze. Ahora bien, al tratarse de una simple fluctuación entre dos sufijos apreciativos de análoga función, no le otorgamos mayor relevancia y, por eso, no consideramos adecuado tratarlo bajo el apartado 2.1.3. "Conceptos presentes, pero con distintos nombres”. Así, este epígrafe quedará consagrado a los ejemplos claros de utilización de significantes distintos para aludir a idénticas realidades (por ejemplo, véase más adelante cómo declivio, caýda y falda se refieren exactamente a lo mismo que anteriormente en español se denominaba alambor, escarpa o escarpe). 
Aunque con actores diferentes, el siglo XVI da muestras asimismo de esta segunda posibilidad, a saber, la de la existencia del concepto gracias a uno de sus dos nombres:

Tabla 4

\begin{tabular}{|l|c|}
\hline Términos & Tratados del siglo XVI \\
\hline Facie & $\varnothing$ \\
Frente & $\sqrt{ }$ \\
\hline Refoseto & Refoso o refosete $^{27}$ \\
Cuneta & $\varnothing$ \\
\hline
\end{tabular}

Y, por lo que respecta al tratado de Lucuze, estas serían también realidades en él contenidas. Ahora bien, mientras que en el segundo caso esto sucede, como viene siendo habitual, gracias a la pervivencia de una de las dos voces del par - aquí de cuneta-, en el primero es la incorporación de una nueva palabra, concretamente cara, la encargada de asegurar la continuidad del concepto: "La cara es la parte más expuesta [del baluarte] y en donde se abre regularmente la brecha, porque solo está defendida por un flanco" (Lucuze 1772: 32-33). ${ }^{28}$

Por otro lado, las parejas terminológicas examinadas vendrían a confirmar que la sinonimia es un fenómeno semántico usual dentro del léxico de la fortificación abaluartada del siglo XVII, al menos en el tratado de Alonso de Zepeda. Al respecto, de acuerdo con Gutiérrez Rodilla:

Es frecuente que en los periodos iniciales de formación de nuevos vocabularios se acuda de manera simultánea a diversos mecanismos neológicos para la formación de los nuevos términos, lo que da cuenta de la vitalidad de cualquier área del saber en sus primeros momentos; pero tal vitalidad lleva aneja la concurrencia sinonímica,

\footnotetext{
27 Como en el caso de molinete $\sim$ molinillo, consideramos también aquí mínima la variación existente entre refoseto, por un lado, y refoso o refosete, por otro.

28 En este caso, estaríamos más bien entonces ante un ejemplo de lo que bajo el tercer apartado hemos denominado "conceptos presentes, pero con distintos nombres"; no obstante, su ubicación aquí responde a la supremacía otorgada en esta ocasión a la situación del concepto en cuestión y de sus términos aparejados en los tratados del siglo XVI.
} 
siendo el paso del tiempo el que favorece la estabilización de unos términos, mientras que otros se van esfumando (1998: 95).

Por consiguiente, dado que los tratados renacentistas no dan cuenta de las realidades posteriormente denominadas molinete o torno y reserva o contraguardia, estos dos pares de sinónimos no deberían extrañarnos, ya que responderían, efectivamente, a los primeros tiempos de vida de ciertos adelantos en materia de defensa. Por el contrario, las concurrencias sinonímicas de facie $\sim$ frente y refoseto $\sim$ cuneta no tendrían tan fácil explicación, al no ser el siglo XVII, del que dichas voces se han tomado, el encargado de inaugurar la construcción de fortalezas abaluartadas con los elementos con ellas referidos y, así, no relacionarse con esa práctica habitual a la que las nuevas disciplinas parecen tender en sus primeros momentos. De esta forma, para estos dos últimos conceptos especializados, tendríamos la siguiente situación lexicológica, de acuerdo con lo reflejado por los tratados analizados:

\section{Tabla 5}

\begin{tabular}{|l|l|l|l|}
\hline Conceptos & s. XVI & s. XVII & s. XVIII \\
\hline $\begin{array}{l}\text { “Cada uno de los dos lados que en un baluarte } \\
\text { salen de los extremos de sus flancos y forman } \\
\text { su ángulo" (Sánchez Orense 2012b: s. v. frente). }\end{array}$ & Frente & $\begin{array}{l}\text { Facie } \\
\text { frente }\end{array}$ & Cara \\
\hline $\begin{array}{l}\text { "Segundo foso pequeño que se forma dentro } \\
\text { del foso, en medio de su superficie ínfima” (Real } \\
\text { Academia Española 1726-1739: s. v. cuneta) }\end{array}$ & $\begin{array}{l}\text { Refosete } \\
\text { (o refoso) }\end{array}$ & $\begin{array}{l}\text { Refoseto } \\
\text { o } \\
\text { cuneta }\end{array}$ & Cuneta \\
\hline
\end{tabular}

Por su parte, también fortín y fuerte constituyen un par de voces equivalentes en la época de Zepeda, de acuerdo con la explicación de este tratadista: "Fortines o fuertes de campaña son todas aquellas fortalezas cuyos ángulos flanqueados distan entre sí menos que los 800 pies de Brusselas, o que los 600 de Francia. De estos se usa en la circumvalación de una plaza y para guardar por un tiempo algún passo peligroso" (1669: 56). Pues bien, de estas dos, solo fuerte está presente en los primeros tratados de fortificación escritos en nuestra lengua, como muestra el siguiente ejemplo extraído del Examen de 
fortificación de González de Medina: "Podrá hazer esto un príncipe muy bien, con tener mucho cuydado de que estén bien fortalecidas las plaças principales de su estado, con muy buenos fuertes en las fronteras y passos por donde puede entrar el enemigo, reguladas de manera que el que las huviere de defender tenga satisfación d'ellas" (1599: 4-5).

Así, pasajes como el anterior, llevan a Lorenzo Celorrio (1996: s. v.) a definir fuerte como la "pequeña fortaleza construida para ocupar un puesto de importancia estratégica”, es decir, otorgándole un significado muy cercano - si no igual- al propuesto por Alonso de Zepeda tanto para fuerte como para fortín. De hecho, en el siglo XVIII, como demuestra el tratado de Lucuze analizado, se mantiene esta misma situación: "Fuerte es una pequeña fortaleza que suele tener cuatro baluartes y se construye para ocupar un puesto de importancia o guardar el paso de un río o montaña [...]. Los pequeños fuertes se dicen también fortines" (1772: 10-11). Hasta aquí estaríamos ante el mismo caso que el de facie $\sim$ frente y cuneta refoseto, es decir, aquel donde en una pareja de sinónimos uno de los dos términos no se encuentra en los primeros tratados de fortificación españoles, pero sí el otro. No obstante, la situación es en esta ocasión más complicada al entrar en juego un elemento léxico más, a saber, castillo, del que podemos afirmar que constituye un claro sinónimo de fuerte en los tratados del siglo XVI analizados, pero del que, sin embargo, no nos atrevemos a afirmar lo mismo - al menos con rotundidad - respecto a la obra de Zepeda.

Es cierto que, en esta, cuando se explican los términos fortín y fuerte, casi al final del capítulo analizado de los "Preludios geométricos", no hallamos la voz castillo. Ahora bien, constituye una de las primeras en ser explicadas, de tal forma que tras ofrecer su significado usual de 'ciudadela o fortaleza construida en el lugar más ventajoso de una villa con la intención de controlar a sus habitantes', usual también del siglo XVI, Alonso de Zepeda matiza que "también se puede usar de ciudadela o castillo para guardar algún paso, pero entonces tendrá otro nombre, porque el de ciudadela es derivado de ciudad y, assí, es el propio quando se construye para guardarla" (1669: 39). Esto es, parece referirse a una segunda acepción de castillo, 
pero, como él mismo advierte, no de ciudadela. Y, a pesar de esta escueta explicación, bien podría tratarse de lo que después denominará con más propiedad fortín o fuerte de campaña, es decir, de la 'pequeña fortaleza construida para ocupar un puesto de importancia estratégica'.

Y, por lo mostrado por Lucuze en su tratado, parece que la polisemia de castillo estaba aún lejos de ser solucionada en el siglo XVIII, pues, si bien es cierto que primero alude a él con su principal significado 'fortaleza típicamente medieval', ${ }^{29}$ admite asimismo su sinonimia con ciudadela, e incluso con fuerte: "La ciudadela ${ }^{30}$ suele tomar el nombre de castillo quando está situada en alguna eminencia [...]. Las ciudadelas y pequeños castillos suelen también llamarse fuertes" (1772: 10). ${ }^{31}$ Por último, debemos mencionar dos términos más igualmente ausentes de los tratados del XVI seleccionados para el cotejo y cuyo tratamiento ahora conjunto responde a su evidente relación con la fortificación anterior a la abaluartada, denominada más propiamente antigua o a la antigua.

Hablamos, en primer lugar, de la voz de origen francés donjón, que Alonso de Zepeda iguala con retirada y reducto, la cual, frente a estas - con múltiples ocurrencias en el corpus del DICTER-, solo ha podido ser localizada en textos centrados, curiosamente, en las construcciones defensivas medievales, como el de Martinena Ruiz, quien al hablar de la torre mayor o del homenaje como uno de los miembros estructurales de aquellas admite que "en algún caso se llega a emplear expresamente el término francés donjón” (1994: 223). Es decir, que se trataría del equivalente galo a lo que más comúnmente en nuestro país se denominó torre del homenaje, por ser en ella "donde se celebraba la ceremonia de juramento de fidelidad u homenaje al señor" (Lorenzo Celorrio 1996: s. v. torre del homenaje).

\footnotetext{
29 "Castillo es una fortaleza a lo antiguo, cercada de fosos y diferentes torres. Hoy son de poca resistencia, pero se conservan algunos por su ventajosa situación, que los hace provechosos en muchos casos particulares" (Lucuze 1772: 10).

30 "Ciudadela es una pequeña fortaleza situada en el recinto de una plaza importante para su mejor defensa y corregir los desórdenes de un tumulto” (Lucuze 1772: 10).

31 Nótese, no obstante, que para Lucuze, frente a Zepeda, también cindadela sería un sinónimo de fuerte.
} 
Así, la presencia del término donjón en un tratado militar español del siglo XVII resulta, cuando menos, curiosa. En cualquier caso, si tenemos en cuenta que en el sistema francés de fortificación medieval su referente se correspondía exactamente con la “tour maîtresse d'un château fort, généralement isolée de la construction, ayant ses fortifications particulières, et servant de dernier refuge aux défenseurs" (TLF: s. v. donjon) (Imbs 1971-1986), quizá su igualación con retirada, pero sobre todo con reducto, ya no resulte tan extraña.

Por fin, respecto a falsabraga, debe aludirse a la estrecha vinculación que mantiene tanto con barbacana como con contramuro, términos que, en contraposición a él, sí se documentan en las obras de milicia del siglo XVI, donde se utilizan en alusión al "muro bajo que para mayor defensa se levanta delante del muro principal" (DRAE: s. v. falsabraga) (RAE 2014); esto es, refiriéndose exactamente a la misma parte de las construcciones defensivas hacia la que, según la lexicografía, apunta falsabraga. Ahora bien, ahondando un poco más en los tratados renacentistas, podemos afirmar que el empleo en estos de dichas voces parecía quedar limitado únicamente a aquellos contextos en los que, por comparación con el nuevo sistema, se mencionaba alguna cuestión de la fortificación previa a la abaluartada, de lo que ofrece un buen testimonio el siguiente ejemplo: "Por tanto, yo tengo una ciudad con muralla vieja y flaca, sin barbacana, a lo antiguo, con sus torreones redondos y muy juntos: ¿cómo lo remendaríades que quedasse en defensa?” (González de Medina 1599: 150).

Por esta razón, los lemas barbacana y contramuro aparecen marcados como anticuados en Sánchez Orense (2012b), al dar cuenta de realidades militares ya superadas en el Renacimiento y, en este sentido, tratarse de vocablos portadores de claras connotaciones negativas en esa época concreta. Así pues, no consideramos que el elemento al que alude falsabraga en el tratado de Zepeda sea totalmente equivalente al denominado contramuro y barbacana en la centuria anterior, lo que nos ha llevado a tratarlo en este subapartado y no, en cambio, en el de "conceptos presentes, pero con distintos nombres".

Como recoge el Diccionario de autoridades (s. v. barbacana), de la "fortificación que se coloca delante de las murallas, que es 
otra muralla más baja, [...] se usaba [...] antiguamente para defender el foso y modernamente ha tenido uso, aunque con el nombre de falsabraga” (RAE [1726-1739] 1990). Pero la información más destacada viene después, cuando los académicos admiten que "hoy está reformado enteramente este género de fortificación, por haberse reconocido que era más contrario que favorable" (Aut: s. v. barbacana) (RAE [1726-1739] 1990). Es decir, si bien el origen de la falsabraga parece estar en las barbacanas o contramuros medievales, su adaptación a las nuevas circunstancias hace de él un elemento nuevo, ${ }^{32}$ lo que, por otro lado, explicaría el recurso al préstamo galo, ${ }^{33}$ con la consiguiente caída en desuso tanto del arabismo barbacana como de la voz derivada contramuro.

\subsubsection{Voces presentes, pero con distinta definición}

En el cotejo efectuado se han detectado asimismo varios términos que, aun estando presentes en otros tratados distintos al de Alonso de Zepeda, en ellos sus correspondientes significados distan del fijado en aquel. Por ejemplo, según el Glosario de fortificación y arte militar renacentistas, retirada designaba, al igual que cortadura, la "nueva construcción defensiva consistente normalmente en un parapeto con cañoneras y merlones, y algunas veces con foso, que suelen hacer los sitiados en los baluartes batidos para impedir que sus enemigos se alojen en la brecha o accedan a la plaza a través de ella" (Sánchez Orense 2012b); así, la retirada constituiría entonces una obra provisional hecha solo cuando fuera necesario, normalmente tras la batida de algún baluarte por parte de los sitiadores. En cambio, se trasluce el carácter permanente de las retiradas en el siglo XVII: "Dentro de los castillos suele haver una retirada para defenderse, siendo abatidos sus muros por el enemigo" (Zepeda 1669: 40). En consecuencia, esta sería la principal diferencia detectada entre la designación de retirada del siglo XVI y la constatada en la centuria siguiente, a la luz del testimonio analizado.

\footnotetext{
32 "Falsabraga es un antemuro baxo al nivel de la plaza, semejante a la barbacana antigua” (Lucuze 1772: 35).

33 "Gal. Del fr. fausse-braye 'bajo terraplén en el foso, en frente de la fortificación principal”” (López Vallejo 2008: s. v. falsabraga).
} 
Ahora bien, a juzgar por el siguiente comentario que Zepeda agrega a su caracterización de retirada — también de donjón y reducto, ambos términos para él con filiación gala-, tampoco en el siglo XVII debió de existir una gran fijación conceptual para todos estos términos: “[Su] forma puede ser en la figura que se quisiere, como en la de una plaza sitiada y batido algún baluarte o lienzo de muralla, pues, siendo una cortadura hecha dentro de la ciudad o castillo y atrincherada, se le puede dar este nombre” (1669: 40). Es decir, como se deduce, no resultaba tampoco extraño denominar con retiradas a las 'cortaduras $\mathrm{u}$ obras provisionales hechas por los defensores de una fortaleza para salir al paso de una brecha abierta en su muro'. Así, tras su significado básico de 'elemento defensivo permanente dentro de un recinto fortificado', habría que sumarle este de 'construcción defensiva temporal', que es justo la designación habitual del término en los tratados del siglo XVI manejados. En definitiva, nos encontramos ante un caso de polisemia, pero que tiende a ir resolviéndose, así, la acepción tradicional va cediendo terreno en favor del nuevo sentido. Por otra parte, a este complejo panorama se añade la sinonimia con la que opera el término en la obra de Alonso de Zepeda, quien sitúa junto al término retirada el de cortadura, además de citar asimismo reducto y donjón para el nuevo significado de 'fortificación permanente'.

En cualquier caso, parece que la lengua reajusta esta difícil situación a lo largo del siglo XVIII, cuando se equilibra esta variación semántica, como se colige a partir de Lucuze, en cuya obra solo se registran cortadura, ${ }^{34}$ por un lado, y reducto, ${ }^{35}$ por otro. Por su parte, barrera evidencia un proceso de especialización terminológica durante el siglo XVII, frente a la centuria precedente, cuando se empleaba con un significado más general: "Barreras son unos troncos

\footnotetext{
34 "Abierta la brecha en la cara, son precisas las cortaduras en el baluarte" (Lucuze 1772: 42). "La cortadura puede tener la figura recta, curva, angular o la de un frente fortificado, según pidiere el terreno. Consiste en un parapeto con su banqueta, que se forma con la tierra que se saca de delante y se guarnece con dos estacadas, una volante y otra detrás del parapeto, al modo que en los fuertes de campaña. Si no hay tiempo, como es regular en la construcción de estas obras, se hacen con faginas, tierra y candeleros” (Lucuze 1772: 315). 35 "Reducto es un pequeño fuerte de figura quadrada o rectángula de 30 a 60 varas de lado, sin otra defensa que la de frente” (Lucuze 1772: 69).
} 
gruessos plantados a 10 pies de distancia el uno del otro, y altos de quatro a cinco pies con otro madero del mismo gordor por travez, fijado en uno de ellos con sus gonzes y cadenas, y con cerraduras para abrirle y cerrarle y dexar entrar el carruage y los que vienen a cavallo. Sirven de detener a los que quieren entrar con ímpetu, y dan lugar de poderles examinar de qué parte vienen" (Zepeda 1669: 56-57). En cambio, la condición de hiperónimo exhibida durante la centuria renacentista se retoma en el siglo XVIII, de acuerdo con el testimonio de Lucuze: "Por barrera se entiende qualquiera obra de estacadas o barras de madera que sirve para cerrar algún paso, asegurar la comunicación y detener al enemigo en las avenidas. Son muchas las especies de barreras, pero las más principales son: el órgano, el peyne, el rastrillo, el caballo de frisa, el puerco espín, el molinillo, la valla, el tambor, los espinos y los abrojos" (1772: 81).

Finalmente, en el caso del compuesto plaza de armas las divergencias provendrían solo del segundo de los significados constatados en Zepeda, al no haberse detectado este en ningún otro tratado manejado, frente a su acepción habitual 'espacio, cuadrado o rectangular, que en la construcción de una fortaleza se reserva en el centro'. ${ }^{36}$ De esta forma, mientras que esta es una unidad pluriverbal monosémica en los tratados del siglo XVI, en la centuria siguiente pasa a ser un claro exponente del fenómeno semántico de la polisemia, al designar tanto "la [plaza] principal de la villa, a la qual vienen a salir las calles mayores de ella" (Zepeda 1669: 42) como "la que está cerca de cada baluarte, o al pie de toda la muralla entre esta y las casas, donde se juntan los soldados en caso de arma para subir y defender la muralla y mudar a los que estuvieren peleando" (Zepeda 1669: 42). ${ }^{37}$ Por lo que respecta al siglo XVIII, es también manifiesta

\footnotetext{
36 Cf. Lucuze (1772), quien especifica, además, que es en este lugar de las fortalezas donde es "capaz de formar la tropa de la guarnición ordinaria” (87).

37 Resulta, cuando menos, interesante apreciar que estas dos acepciones de plaza de armas son aglutinadas bajo una única definición por parte de Raimundo Sanz, el autor del primer diccionario militar del español: "Es un terreno libre y espacioso, sea en medio de ella, a donde concurren las principales calles, o bien entre el terraplén y las últimas casas. Esta sirve de parage señalado para concurrir en ella la guarnición quando ay una alarma inopinada, o en general quando es necessario executar las órdenes del governador" (Sanz [1749] 2007:
} 
la polisemia del término plaza de armas, si bien en esta etapa ocupa el lugar reservado a la segunda acepción la relativa a 'cada uno de los espacios que en la estrada encubierta de una fortaleza se dejan para su defensa', ${ }^{38}$ a la cual los tratadistas del siglo XVI denominaban simplemente plaza (vid. Sánchez Orense 2012b: s. v.).

\subsubsection{Conceptos presentes, pero con distintos nombres}

Para referirse a uno de los miembros más característicos de las fortaleza modernas, el constituido por el terreno o superficie que desde el parapeto del camino cubierto va descendiendo, con una pendiente o declive muy suave, hasta alcanzar el nivel de la campaña, los ingenieros y demás especialistas de finales del siglo XVI y principios del XVII disponían no de una, sino de varias unidades léxicas, a saber, arcén del foso o su elipsis arcén, los italianismos árgine y escarpa e, igualmente, la voz patrimonial vallado; lo que ya concluimos en Sánchez Orense (2012a: 171-172); situación que, entre otras cosas, vendría a demostrar, primero, la explotación por parte del léxico militar renacentista de los distintos recursos disponibles para la creación de neologismos, así como, segundo, las numerosas voces sinonímicas en él presentes. Ahora bien, curiosamente, ninguna de aquellas fue capaz de imponerse al resto con el transcurrir del tiempo, siendo finalmente un nuevo término, concretamente explanada, el encargado de la designación de este concepto; razón que explica el uso exclusivo de este tanto por Zepeda como por Lucuze.

Además del anterior, son varios más los casos que podrían citarse de pervivencia temporal de ciertos conceptos especializados de la milicia con diferentes significantes; así, uno de ellos es el constituido por los tríos sinonímicos declivio, caída y falda, por un lado, y alambor, escarpa o escarpe, por otro. Es decir, frente a estos tres últimos vocablos, los específicamente utilizados en el siglo XVI para aludir al 'plano inclinado que muchas veces adoptaban los muros de

s. v. plaza de armas de una ciudad de guerra). Para más datos sobre esta importante obra lexicográfica, consúltense Sánchez Orense (2013b) y Sánchez Orense (2014).

38 "En los entrantes del camino cubierto, y algunas veces en los salientes, se hacen plazas de armas, capaces de formar la tropa que ha de salir, o se retira o defiende la misma estrada encubierta” (Lucuze 1772: 38). 
las fortificaciones', ${ }^{39}$ constatamos en el tratado de Zepeda aquel otro triplete, que apunta exactamente en la misma dirección: "El declivio, caýda o falda no es otra cosa que el pendiente que se da a una [...] muralla para que assí tenga más pie y fuerza mayor para sustentarla, el qual es interior o exterior" (1669: 43). Por su parte, el tratado del siglo XVIII analizado sí muestra la presencia de uno de estos tres términos (declivio); de esta forma, Lucuze desecha tanto caída como falda, a la vez que añade una nueva voz equivalente: pendiente.

En el caso de querer aludir a la "distancia entre la muralla y el foso o falsabraga, para que cayga en él, y no en el foso, la tierra que se desmoronare de la muralla" (Zepeda 1669: 46), los españoles de mediados del siglo XVII podían recurrir al compuesto bordo de la muralla, cuyo equivalente en francés es berme.$^{40}$ Ahora bien, a la luz de los testimonios de Lechuga y Ufano, unos años antes, en lugar del compuesto, se empleaba el término univerbal banqueta: ${ }^{41}$

A las que an de ser de tierra es menester que, del principio de sus murallas hasta el del fosso, se les dexe tanta tierra como cinco pies en todo su circuito, que llaman banqueta, para que la fábrica quede segura y que baje al fosso a escarpa para mayor firmeza, mirando que desde la dicha banqueta se a de tomar la medida de la que an de tener los fossos (Lechuga 1611: 249).

Si en el arçe del fosso y banqueta del pie de la muralla uviere plaça cubierta de orejones, tenazas o bestiones para alojar pieças, algunas de

39 Cf. DSAL (s. v. escarpa). Por otro lado, y de acuerdo con lo expuesto hasta ahora, la voz escarpa sirve de nuevo para ejemplificar otra de las conclusiones que sobre la terminología militar renacentista se sostienen en Sánchez Orense (2012a: 172), a saber, la de "la fuerte presencia de unidades léxicas polisémicas en ella".

40 "Bordo de la muralla, que llama el francés berme" (Zepeda 1669: 46). De acuerdo con el TLF (s. v. berme) (Imbs 1971-1986), la primera documentación de esta voz francesa con el sentido especializado de la fortificación aquí reseñado se localiza en el año 1676.

${ }^{41}$ Como se constata en Sánchez Orense (2012b), este término da cuenta a finales del siglo XVI y principios del XVII, durante los primeros años de desarrollo e implantación del nuevo sistema de fortificación abaluartado, de una fuerte polisemia; típico, por otro lado, de esos períodos iniciales de cualquier área del saber (cf. Gutiérrez Rodilla 1998: 95). En cualquier caso, también entonces su significado especializado básico y más general era el de "escalón o grada de un pie y medio de alto, y de 4 a 5 de ancho, para que, levantándose sobre ella el mozquetero, pueda tirar (como se ha dicho) por ensima del parapeto" (Zepeda 1669: 45). 
menor calibre serán de grandíssimo effecto, porque de tales puestos resulta el mayor daño que los sitiadores reçiben (Ufano 1613: 180).

Por lo que respecta al siglo XVIII, se constatan, en cambio, desplazamientos terminológicos: por un lado, la lengua incorpora el préstamo (berma), pero, a su vez, de forma endógena recurre a la sufijación apreciativa, acuñándose bancón frente a banqueta: "En países que carecen de buena mampostería y abundan de praderías revisten con tepes o céspedes el terraplén, dexando entre este y el foso un espacio de cinco u seis pies, llamado el bancón o berma, en que ponen estacada, para que las ruinas de la muralla no caygan en el foso" (Lucuze 1772: 26). Por último, se observa el par léxico fortificación de afuera (Zepeda) / obra exterior (Lucuze), del cual es la segunda unidad pluriverbal la que termina por imponerse, a juzgar por la documentación lexicográfica: "Mil. Obra que se hace de la contraescarpa afuera para mayor defensa” (DRAE: s. v. obra exterior) (RAE 2014). En cambio, no hemos detectado en el siglo XVI ninguna voz alusiva para este concepto, lo que no obsta para su existencia, ${ }^{42}$ sino que, seguramente, dado aún el pequeño conjunto formado por esta modalidad de obras defensivas, ${ }^{43}$ los tratadistas de aquel entonces no se vieron en la necesidad de aludir a él mediante un término preciso.

\section{Conclusiones}

Tras el cotejo realizado entre el Epitome de la fortificación moderna (1669) de Alonso de Zepeda y otros tratados sobre arquitectura militar son varias las conclusiones allegadas, las cuales ofrecerán una panorámica sobre la evolución del léxico de la fortificación abaluartada desde su nacimiento hasta el siglo XVIII, su momento de mayor esplendor.

En primer lugar, queremos destacar que, aunque nos hayamos centrado en las divergencias, son mayoritarias las regularidades

\footnotetext{
42 Piénsese, por ejemplo, en el revellín, construcción de este tipo típicamente presente en las primeras fortalezas abaluartadas.

43 Al menos en comparación con la situación reflejada por el tratado de Zepeda y, sobre todo, por el de Lucuze.
} 
terminológicas. De hecho, de las setenta palabras tomadas en consideración, hasta cuarenta se mantienen sin cambios relevantes de unos tratados a otros, lo que supone más de un $57 \%$ de homogeneidad. Como todo, se advierten pequeñas modificaciones formales, derivadas por ejemplo de su adecuación a las normas ortográficas del español, ${ }^{44}$ pero, en ningún caso, alteraciones de significado o discrepancias designativas. De esta constatación, puede colegirse que el vocabulario español de la fortificación abaluartada se mantiene en lo esencial inalterable desde finales del siglo XVI, cuando surgen los primeros tratados en torno a esta temática, hasta casi el último cuarto del siglo XVIII, centuria en que Lucuze realiza su contribución a la misma.

Por otra parte, con respecto a las divergencias, consideramos probada una mayor ausencia de los términos extraídos de Zepeda en las primeras obras de fortificación renacentistas, que no en el trabajo de Lucuze, ya que, de los diecisiete señalados por su inexistencia en cualquiera de los textos cotejados, solo la de siete tiene lugar en este último, frente a los quince que faltan en aquellas. Es más, gracias a la aparición de términos equivalentes, no son realmente siete los conceptos de especialidad a los que da cabida Zepeda y que, sin embargo, no se encuentran en el tratado de Lucuze, sino solo uno, el asociado a la voz frasa. Esto es, el hecho de que Lucuze se valga de molinillo, contraguardia, cara, cuneta y reducto conduce a que en su obra sí estén finalmente representados los conceptos a los que en su lugar o de manera sinonímica Zepeda denomina torno, reserva, facie o frente, refoseto y donjón, respectivamente.

En cambio, en el caso de los tratados consultados a través del corpus del DICTER, hemos contabilizado hasta ocho conceptos

44 Sería el caso, entre otras, de esplanada, escrita de este modo en la obra de Zepeda y que, sin embargo, muestra ya su forma moderna en el tratado de Lucuze. Mucho más interesante resulta la gran variedad formal asociada a las designaciones de la obra de fortificación exterior que, normalmente situada delante de alguna cortina, se componía de dos frentes formando un ángulo saliente hacia la campaña, al ser estas múltiples, al menos según datos del DICTER. Así, en los textos de finales del siglo XVI y principios del XVII se recogen hasta cuatro variantes para este concepto (rebelín, rebellín, revelín, revellín), ninguna de las cuales, sin embargo, es la utilizada por Zepeda, quien prefiere la forma con vacilación de vocal átona inicial ravelín, ajena a cualquier otro texto de nuestra historia, tal como se infiere de la consulta del CORDE. 
de fortificación por ellos desconocidos, entre los que sobresalen especialmente dos campos semánticos, a saber, el de las barreras o construcciones para impedir el paso, primero, así como el relativo a las obras exteriores, en segundo lugar; precisamente, los dos ámbitos de la fortificación abaluartada que más se fueron complicando y perfeccionando con el tiempo. Esto supone, en definitiva, que en torno al año 1669, cuando Zepeda publica su Epítome de la fortificación moderna, este sistema de arquitectura defensiva ya había superado sus primeros titubeos, propios de la instauración de una nueva ciencia, logrando, así, superarse y completarse.

Ahora bien, pese a la relevancia que evidentemente adquieren las voces de Zepeda sin equivalente en otras obras ( $c f$. 2.1.1.), es nuestra intención remarcar ahora el mayor calado que revisten las situaciones contempladas en los otros dos apartados establecidos al efecto (cf. 2.1.2. y 2.1.3.), al ser estas las verdaderamente conflictivas a la hora de ser trasladadas a una determinada obra lexicográfica. Por ejemplo, en el supuesto de tener que confeccionar un glosario especializado sobre el léxico de la fortificación abaluartada, ¿qué decisiones respecto al término retirada, por citar solo uno, serían las más adecuadas? ¿Establecer, a la vista de sus documentaciones, una única acepción para el siglo XVI, frente a seleccionar las dos relevantes de la centuria siguiente, entre las cuales la más importante sería la nueva y no la tradicional? Aún más, ¿cómo habría que reflejar su desaparición del texto de Lucuze?

De modo paralelo, ¿`cómo habría de señalarse en dicho glosario la evidente filiación de tipo semántico existente entre banqueta (datada a principios del siglo XVII), bordo de la muralla (hacia la mitad del siglo XVII) y berma o bancón (siglo XVIII)? Igualmente, ¿cómo dar cuenta de la mejor manera posible de que el vocablo castillo posee dos acepciones especializadas dentro del ámbito de la fortificación moderna, si bien su uso va decreciendo en detrimento de un italianismo, ciudadela, en el caso de la primera, y del préstamo semántico del francés, fuerte, ${ }^{45}$ en la segunda?

\footnotetext{
45 "Como término de fortificación, el sustantivo fuerte [1595, Fuenmayor] pudo imitarse del fr. fort [1265]” (DECH) (Corominas y Pascual 1980-1991).
} 
En resumen, teniendo en cuenta estas complejidades, consideramos que son realmente este tipo de casos, de gran trascendencia en la historia del léxico de cada lengua, los que más precisan, tanto para su transmisión como para su completo entendimiento, de un diccionario histórico, afortunadamente en proceso de redacción. ${ }^{46}$ En este sentido, nuestra intención ha sido en todo momento contribuir, en la medida de nuestras posibilidades, a un mejor conocimiento de la pequeña parcela que constituye el léxico de la fortificación abaluartada y tratar de simplificar, de esta forma, el arduo trabajo que tienen ante sí los lexicógrafos encargados de este proyecto.

\section{Referencias bibliográficas}

Bravo Nieto, Antonio

1994 "La racionalización del espacio defensivo en el Renacimiento. Dos tratados de arquitectura militar en España". Boletín de arte. $15,69-89$.

Campillo, Antonio

2008 La fuerza de la razón. Guerra, estado y ciencia en el Renaci-

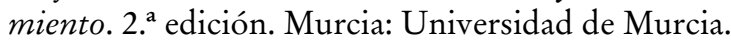

Corominas, Joan y José Antonio Pascual

1980-1991 Diccionario crítico etimológico castellano e hispánico. Madrid: Gredos. (DECH).

Díaz Capmany, Carlos

2004 La fortificación abaluartada. Una arquitectura militar y politica. Madrid: Ministerio de Defensa.

Galindo Díaz, Jorge Alberto

1996 El conocimiento constructivo de los ingenieros militares del siglo XVIII. Un estudio sobre la formalización del saber técnico a través de los tratados de arquitectura militar. Tesis Doctoral. Universidad Politécnica de Catalunya. Consultado: 31 de marzo de 2016. <http://www.tdx.cat/bitstream/ handle/10803/6105/01TESIS.pdf?sequence $=1>$.

\footnotetext{
46 De hecho, ya está disponible, en la página web <http://web.frl.es/DH>, una muestra bastante clarificadora (constituida por 1365 artículos) de lo que será esta vasta obra (cf. Pascual 2015: 8).
} 
GonzÁlez de Medina Barba, Diego

1599 Examen de fortificación. Madrid: Pedro Várez de Castro.

Gutiérrez Cuadrado, Juan (dir.)

1996 Diccionario Salamanca de la lengua española. Madrid: Santillana, Ediciones Universidad de Salamanca. (DSAL).

Gutiérrez Rodilla, Bertha

1998 La ciencia empieza en la palabra. Análisis e historia del lenguaje científico. Barcelona: Ediciones Península.

ImBS, Paul (dir.)

1971-1986 Trésor de la langue française. Dictionnaire de la langue du $X I X e$ et $d u X X e$ siècle. París: Centre National de la Reserche Scientifique-Gallimard. (TLF).

Instituto de Investigación Rafael Lapesa de la Real Academia Española 2013 Corpus del Nuevo diccionario histórico (CDH). Consultado: 6 de abril de 2016. <http://web.frl.es/CNDHE>.

2013 Nuevo diccionario bistórico de la lengua española (NDHE). Consultado: 6 de abril de 2016. <http://web.frl.es/DH>.

Lechuga, Cristóval

1611 Discurso del Capitán Cristóval Lechuga, en que trata de la Artillería y de todo lo necessario a ella. Milán: Marco Tulio Malatesta.

López Piñero, José María

1979 Ciencia y técnica en la sociedad española de los siglos XVI y XVII. Barcelona: Labor universitaria.

López Piñero, José María, Thomas F. Glick, Víctor Navarro Brotóns y Eugenio Portela Marco (eds.)

1983 Diccionario histórico de la ciencia moderna en España. Dos volúmenes. Barcelona: Ediciones Península.

López Vallejo, M.a Ángeles

2008 "Glosario de términos militares". En Historia del léxico militar en el español áureo: La conquista de Granada, el conflicto bispano-italiano y las guerras de Flandes. Tesis doctoral. Granada: Repositorio Institucional de la Universidad de Granada, 199-1240.

LORENZO CELORRIO, Ángel

1996 Compendio de vocablos referidos a los castillos. Madrid: Ediciones Lancia. 
Lucuze, Pedro de

1772 Principios de fortificación. Barcelona: Thomas Piferrer.

Mancho, María Jesús (dir.)

s/a Diccionario de la Ciencia y de la Técnica del Renacimiento (DICTER). Salamanca: Ediciones Universidad de Salamanca. $<$ http://dicter.eusal.es/>.

Martinena Ruiz, Juan José

1994 Castillos reales de Navarra (siglos XIII al XVI). Pamplona: Gobierno de Navarra, Institución Príncipe de Viana.

Merino Peral, Esther

2002 El arte militar en la época moderna: los tratados «de re militari» en el Renacimiento. 1536-1671. Aspectos de un arte español. Madrid: Ministerio de Defensa, Secretaria General Técnica, Centro de Publicaciones.

PARKER, Geoffrey

2002 La revolución militar. Innovación militar y apogeo de Occidente. 1500-1800. Madrid: Alianza Editorial.

Pascual, José Antonio

2015 "Introducción a una celebración lexicográfica: a propósito de la reciente publicación de un millar de palabras del NDHE en el portal de la RAE”. Estudios de Lexicografía. 3, 7-14.

Real Academia Española

[1726-1739] 1990 Diccionario de autoridades. Madrid: Gredos. (Aut.).

2014 Diccionario de la lengua española. 23 edición. Barcelona: Espasa Libros. (DRAE).

s/f Banco de datos. Corpus diacrónico del español (CORDE). Consultado: 6 de abril de 2016. <http://www.rae.es>.

Rojas, Christóbal de

1598 Teórica y práctica de fortificación. Madrid: Luis Sánchez.

SÁnchez Martín, Francisco Javier

2013 "La conciencia terminológica de los matemáticos e ingenieros renacentistas y su preocupación por la divulgación científica”. Anuario de Estudios Filológicos. 36, 147-164.

SÁNChez Orense, Marta

2012a La fortificación y el arte militar en los tratados renacentistas en lengua castellana: estudio lexicológico y lexicográfico. 
Salamanca: Ediciones Universidad de Salamanca, Colección Vítor, 322.

2012b "Glosario de fortificación y arte militar renacentistas". En La fortificación y el arte militar en los tratados renacentistas en lengua castellana: estudio lexicológico y lexicográfico. Salamanca: Ediciones Universidad de Salamanca, 199-733.

2013a "Los aportes de las lenguas francesa e italiana en la conformación de la terminología militar renacentista del español”. Debate Terminológico. 10, 37-54.

2013b "El Diccionario militar (1749) de Raimundo Sanz y la incorporación de galicismos al castellano”. Anuari de Filologia. Estudis de Lingüistica. 3, 159-183.

2014 "Un ejemplo de la corriente traductora en la lexicografía especializada: el Diccionario militar (1749) de Raimundo Sanz". En Traducción y difusión de la ciencia y la técnica en España (siglos $X I V-X I X)$. Eds., Julia Pinilla y Brigitte Lépinette. Valencia: Publicacions de la Universitat de València, 403-423.

SANZ, Raimundo

[1749] 2007 Diccionario militar. Edición y estudio de Francisco GagoJover y Fernando Tejedo-Herrero. Zaragoza: Institución "Fernando el Católico".

TERradas, Esteban

1946 Neologismos, arcaísmos y sinónimos en plática de ingenieros. Madrid: S. Aguirre.

Ufano, Diego

1613 Tratado de la Artillería. Bruselas: Juan Momarte.

VARela Merino, Elena

2009 Los galicismos en el español de los siglos XVI y XVII. Madrid: CSIC.

Zepeda y Adrada, Alonso de

1669 Epitome de la fortificación moderna, assí en lo regular como en lo irregular, reducida a la regla y al compás por diversos modos y los más fáciles para mover la tierra [...]. Bruselas: Francisco Foppens. 